\title{
Editorial
}

\section{Recentering the History of Physics}

This past summer, the History of Science Society met in Utrecht, convening its annual meeting in Europe for the first time in its ninety-five-year history. As Jeroen van Dongen points out in this issue, however, the history of science was not entering new territory so much as it was returning to its ancestral homeland. It took root as an institutionalized discipline early in the Netherlands - in 1944, when Eduard Dijksterhuis was appointed to teach history of science at the University of Amsterdam, a decade before the first similar professorship in the United States was created at the University of Oklahoma. Those early iterations of the field, wherever they were practiced, focused, with just a few notable exceptions, on European science. As van Dongen points out, it was through a series of "decenterings" that we arrived at the form of the discipline we recognize today.

Thomas Kuhn, as evident in his noted dispute with Martin Klein over how to interpret Max Planck's introduction of the quantum, insisted that historians decenter the now. He brought an uncompromisingly historicist eye to past conceptual developments that remains at the heart of the field's identity. But his focus remained principally European, and principally on the major figures of the scientific and quantum revolutions. Gradually, with the rise of history of science programs and departments in the United States, Europe was decentered as well. A new generation of American-trained historians of science trained their eyes on what has sometimes been called the "American century." Alongside this transition came efforts to decenter the traditional icons of the history of science, such as Nicolaus Copernicus, Galileo Galilei, and Isaac Newton, and to consider both earlier and more disparate geographical roots of modern science.

In the course of the field's evolution, physics was also decentered. New, lively interest in the history of biology, medicine, technology, and the social sciences reframed the field's central questions. Turning away from models of the solar system, historians of science scrutinized model organisms. Interest in field theories gave way to fascination with the field sciences. Less magnetism; more Mesmerism. Physics no longer defines the discipline's agenda as it did when Kuhn, Klein, and Dijksterhuis were among its leading lights. Many leading graduate programs now have no faculty dedicated to the subject and it is possible, even common, to complete a $\mathrm{PhD}$ in the history of science without gaining anything more than a passing familiarity with key questions from the history of physics. 
But, as van Dongen points out with respect to Europe, decentering can be celebrated, rather than greeted with dismay. The spread of the history of science to new regions, new time periods, and new subjects is a sign of its vibrancy, which can reflect back on decentered areas. That is an important lesson to keep in mind if we want to ask how to recenter the history of physics - to ask what it would look like to have the history of physics play a larger role in defining the agenda of the history of science. Doing so requires engaging with the changes that decentering brought about in the first place.

Christian Ruhl's contribution to this volume provides an apt example of what that looks like. Ruhl begins with his own observation of the decentering of physics: John Wheeler's remarkable statement that "it's better to forget the physics" when advising military leaders on nuclear policy. The very expertise that give American physicists policy influence during the Cold War had to be set aside in the course of exerting that influence. Ruhl's is a story that emerges from the very series of decenterings van Dongen highlights: it is distinctly American, it seeks to occupy the peculiar way of thinking that marked Cold War nuclear strategy, and it explicitly sets the conceptual development of physics aside-at the advice of one of its virtuosi-in order to explore its political dimensions. But in so doing it sheds important light on physics as a Cold War cultural institution, one that could shape the fates of nations even when it explicitly set aside the source of its authority.

Robert P. Crease Joseph D. Martin Richard Staley

Publisher's Note Springer Nature remains neutral with regard to jurisdictional claims in published maps and institutional affiliations. 